Fecha de recepción: noviembre 2020 Fecha de aprobación: diciembre 2020 Fecha publicación: marzo 2021
Futbolistas de élite como instagrammers de moda: Ronaldo y Messi

Zineb El Habchi Mahir ${ }^{(1)}$ y

Resumen: Instagram constituye un escaparate de moda con más de 1.000 millones de usuarios. Este trabajo investiga las cuentas de Cristiano Ronaldo y Lionel Messi, como dos de los influencers con más seguidores en Instagram. Se analiza cuantitativa y cualitativamente su actividad en la red social de fotografías, durante un año natural, de julio de 2019 a julio de 2020. Se concluye que las publicaciones promocionales no superan el 30\% del total de las publicaciones; apenas el 3\% de los seguidores dan un like; menos del 1\% hace un comentario; y todavía priman los posts de fotografías sobre los posts de vídeos, aunque Instagram ofrezca varios formatos (vídeos cortos, IGTV, reels y stories destacados).

Palabras clave: Instagram - influencers - moda - deporte - fútbol - Ronaldo - Messi - redes sociales - publicidad - imágenes.

[Resúmenes en inglés y portugués en la página 154]

(1) Magíster y Graduada en Periodismo. Ex becaria de colaboración (Ministerio de Educación y Formación Profesional) en la Facultad de Ciencias de la Información, de la Universidad Complutense de Madrid.

(2) Doctora en Ciencias de la Información. Coordinadora del Grado en Periodismo y Profesora Titular en la Facultad de Ciencias de la Información y miembro del Instituciones de Investigaciones Feministas, de la Universidad Complutense de Madrid.

\title{
Introducción
}

Al empezar 2020, más de 4.500 millones de personas usaban Internet en el mundo y 3.800 millones eran usuarios de redes sociales. Esto suponía que el $60 \%$ de la población mundial accede regularmente al mundo digital y el $45 \%$ de la misma población también estaba en redes sociales (We are Social y Hootsuite, 2020). A la espera de conocer los mismos datos, actualizados a finales del mismo año, podemos atender a los datos oficiales del Instituto Nacional de Estadística español (INE, 2020), que fija que el 93,2\% de la población española de 16 a 74 años ha utilizado Internet en los últimos tres meses, 2,5 puntos más que 
en 2019, y supone un total de 32,8 millones de usuarios. Asimismo, el informe fija que el uso de Internet es una práctica mayoritaria en los jóvenes de 16 a 24 años, con un 99,9\% en los hombres y un $99,6 \%$ en las mujeres. Y al aumentar la edad, desciende ligeramente el uso de Internet en hombres y mujeres, siendo el porcentaje más bajo el que corresponde al grupo de edad de 65 a 74 años: un 70,5\% para los hombres y un 68,9\% para las mujeres (INE, 2020).

De acuerdo con otros informes internacionales, la población digital pasa 6 horas y 43 minutos conectada cada día (We are Social y Hootsuite, 2020) y al menos, la mitad de ese tiempo se ejecuta desde un teléfono móvil. Los usuarios de redes sociales dedicaron una media de 2 horas y 24 minutos diarios a navegar e interactuar por sus perfiles, lo que supone más de un tercio de todo el tiempo que dedican al mundo digital (We are Social y Hootsuite, 2020). Las redes sociales elegidas fueron, en orden decreciente: Facebook, con más de 2.111 millones de usuarios; YouTube, con más de 1.900 millones de usuarios; Instagram, con más de 1.000 millones de usuarios; y Twitter, con más de 325 millones de usuarios (We are Social y Hootsuite, 2020).

En abril de 2012, Facebook adquirió Instagram por 1.000 millones de dólares y pasó a ser propiedad de la empresa de Mark Zuckerberg. Con esto, Facebook e Instagram juntas se sitúan muy por delante de su primera competidora directa, YouTube, en número de usuarios. Instagram es la red favorita de los millennials, quienes declaran que utilizan hasta 5 redes sociales a la vez (Bernárdez, Padilla y Sosa, 2019; IAB Spain, 2019a; Kijek, Angowski y Skrzypek, 2020); y la mayoría de sus usuarios, el 66\%, tiene menos de 39 años, siendo un 54\% mujeres y un 46\% hombres (The Social Media Family, 2020; Clary, Markham y Myers-Bowman, 2020).

Instagram es una red social sencilla, que ofrece subir fotos y comentarlas; o publicar vídeos de menos de un minuto de duración, llamados Instagram Stories, que se borran a las 24 horas. En 2018, lanzó IGTV (Instagram TV), una herramienta de vídeos verticales de hasta una hora de duración con la que Mark Zuckerberg buscaba competir con YouTube. Una parte importante de Instagram e IGTV es el variado abanico de filtros gratuitos y sencillos de usar, que ofrece para las fotografías y los vídeos. Dan acabado y personalizado y profesional a todas las imágenes y la simplicidad de su uso se erige como una de las fórmulas de éxito de la red social.

En marzo de 2019, lanzó Instagram Checkout, una herramienta que permite hacer compras sin salir de la app y sin tener que cerrar la aplicación y abrir el navegador, para visitar la web del producto y consultar su precio. Esta ampliación mejora la experiencia del usuario, elimina las interrupciones y ofrece una compra segura y rápida. Y en agosto de 2020, tras el confinamiento mundial por la COVID-19 y el crecimiento exponencial de TikTok, Instagram lanzó los reels. Son vídeos cortos de 15 segundos, pero de vida permanente, ya que no desaparecen a las 24 horas como los stories, y se asemejan directamente a los mini-vídeos de la red social china, que le podría robar usuarios. Los reels también ofrecen herramientas gratuitas de edición, filtros, inserción de audios o música, pegatinas, cambios de velocidad y otros accesorios que también ofrece TikTok.

En este entorno de tantas posibilidades, Instagram se erige como escaparate y tienda de múltiples productos y servicios, sustituyendo cualquier tienda física y ofreciendo más información y valores añadidos a cambio (Padilla y Oliver, 2018). Las marcas de moda se 
han adaptado rápidamente, entendiendo las posibilidades y colaborando con celebridades e influencers, con varios millones de usuarios. Este trabajo se centra concretamente en dos futbolistas de élite, del top ten mundial en usuarios de Instagram en diciembre de 2020: Cristiano Ronaldo (@cristiano, 247 millones de seguidores) y Lionel Messi (@leomessi, 172 millones de seguidores). Los dos se convierten en valiosos influencers de la moda y sus publicaciones tienen más audiencia e impacto que cualquier publicidad convencional, en cualquier medio masivo de máxima audiencia.

\section{Objetivos y metodología}

En el entorno de consumo digital y de actividad profusa de redes sociales que se ha comentado, este trabajo plantea los siguientes objetivos:

- Explorar de manera mixta (cuantitativa y cualitativa) las cuentas de Instagram de Cristiano Ronaldo (@cristiano) y Lionel Messi (@leomessi).

- Detectar y comentar las diferencias entre las dos cuentas: número de seguidores, número de publicaciones, productos de moda que anuncian, sector de moda que anuncian, formas de comunicar los patrocinios y las colaboraciones, e impacto.

- Explorar si se utilizan más fotos o más vídeos y por qué.

- Dilucidar la influencia de los deportistas como modelos de ropa, más allá de su primera actividad profesional.

La metodología de la investigación se basa en dos cimientos correlativos, que buscan resultados interesantes, inéditos y concluyentes, más allá de lo meramente descriptivo:

- Investigación bibliográfica longitudinal de los conceptos de celebridad e influencer. Se ha realizado a través de fuentes bibliográficas de primer nivel: Scimago Journal \& Country Rank, Dialnet, E-Prints UCM, Elsevier online, SAGE Journals, Taylor and Francis online, E-Prints UCM y Academia.edu. Esta fase forma parte del trabajo y elaboración del Tesauro del Proyecto I+D Programa de excelencia, Subprograma estatal de generación de conocimiento, Ministerio de Economía, Industria y Competitividad, titulado Produsage cultural en las redes sociales: industria, consumo popular y alfabetización audiovisual de la juventud española con perspectiva de género, referencia FEM2017-83302-C3-3-P y duración: 01/07/2018-01/01/2022; y del proyecto de investigación de Zineb El Habchi Mahir, como Becaria de colaboración Ministerio de Educación y Formación Profesional en el curso 2019-2020, en la Facultad de Ciencias de la de la Universidad Complutense de Madrid.

- Estudio diacrónico, cuantitativo y cualitativo, de las cuentas de Instagram Cristiano Ronaldo y Leo Messi: me gusta o likes; comentarios e índice de respuesta; fechas; hashtags o etiquetas; marcas promocionadas en sus perfiles; resultados. El análisis abarca un año natural completo: desde el 1 de julio de 2019 al 31 de julio de 2020. Entre septiembre y diciembre de 2020, se han analizado los datos para este trabajo, pero sin contabilizar las nuevas publicaciones. Dentro de los posts publicados sólo se toman para los análisis aquellos 
en los que los protagonistas aparecen solos. Es decir, quedan excluidos los selfies con otras personas o imágenes en las que Ronaldo y Messi no aparecen. Esta selección se hace con la finalidad de recopilar información sobre el tipo relación que tienen los protagonistas con su comunidad de seguidores, sin interferencias. Así, el corpus definitivo está formado por 391 posts: 257 de Cristiano Ronaldo y 134 de Leo Messi. Su validez queda refrendada porque supone un alto porcentaje de publicaciones sobre el total de toda la cuenta y concretamente, casi un tercio de todas las publicaciones de la cuenta de Messi incluyendo selfies, fotografías con otras personas o fotografías de objetos, que no se computan en este trabajo. De acuerdo a lo anterior, la cantidad de publicaciones no se puede valorar en términos absolutos, como en otros trabajos, sino en términos relativos, por el alto porcentaje que supone dentro de dos cuentas con varios años de antigüedad.

El análisis cuantitativo se ha realizado publicación a publicación por las propias autoras, a través de una ficha de recopilación de datos: fecha de publicación, marca o marcas etiquetadas, etiqueta en la foto o etiqueta en la descripción, descripción de la foto, número de comentarios, número de respuestas a los comentarios y número de me gusta. No se ha recurrido a ningún API (Application Programming Interface) o programa de medición de redes sociales, para asegurar que no se obviara o se filtrara ninguna publicación erróneamente. El análisis cualitativo se ha realizado también publicación a publicación por las autoras, añadiendo a la ficha de análisis estos parámetros: marca patrocinadora, producto de la marca anunciado, sector de producción o servicios de la marca, target socio-económico de la marca.

\section{Sobre las celebridades y los influencers}

En junio de 2020, por primera vez, la inversión publicitaria digital en España superó la inversión en televisión tradicional (InfoAdex, 2020). En este entorno consolidado, el 38,6\% de los fondos invertidos en medios controlados o convencionales se destinó a comunicación digital. Dentro del sector, los formatos de Display y Vídeo, incluidas las redes sociales son los que reciben un mayor desembolso (InfoAdex, 2020). A estos datos hay que añadir la comunicación no convencional o below the line, que sigue creciendo exponencialmente cada año y que contiene la inversión en branded content, influencers o publicidad nativa. En la misma línea, el informe Top Tendencias Digitales (IAB Spain, 2019b) auguró que la publicidad en redes sociales habría de vivir una innovación radical, con nuevas formas de colaboración con influencers más originales, inmersivas y eco-conscientes. Los microinfluencers ganarían seguidores y credibilidad, frente a los macroinfluencers, que ya tienen millones de seguidores per se y están más lejos del entorno social y económico de su audiencia (IAB Spain, 2019b, p. 14). De hecho, el 46\% de los profesionales españoles ha contratado los servicios en redes sociales de influencers, principalmente en Instagram. De estos, el 87\% está muy o bastante satisfecho con las acciones de los influencers (IAB Spain, 2019a). Instagram captaría el 36\% de la inversión publicitaria en redes sociales, situándose como segunda red social. La adelanta solamente Facebook, con el 56\% de mercado (IAB Spain, 2019a). 
Los propios influencers consumen promociones de otros influencers. Según el I Estudio de Influencers de Moda, el 85,9\% de los influencers compra ropa tras vérsela a otro influencer en las redes sociales. El $81 \%$ afirma que compraría ropa anunciada por otro influencer bajo la etiqueta \#ad. Y un $41 \%$ de los influencers asegura que compra directamente desde Instagram (Socialpubli, 2019). Una de las primeras definiciones académicas del influencer en España es la del Diccionario LID Marketing directo e interactivo (van Nispen et al., 2012), que recalcaba la capacidad del influencer para captar nuevos clientes o fidelizar a los que ya se poseen. Fernández, Hernández y Sanz (2018) explicaron que el influencer combina la gestión de su marca personal con el rol de prescriptor; y que cuando se concentra en temas políticos, suele ser moderado y a veces, humorístico e irónico. Sobre la prescripción es muy valiosa también la investigación de Bergkvist, Hjalmarson y Mägi (2016), ya que alegan que sólo se consigue si se dan tres factores: la experiencia de la celebridad, la credibilidad de la unión entre la marca y el influencer, y la percepción positiva de las razones del influencer para recomendar esa marca.

Los estudios científicos de alto impacto sobre influencers de moda son numerosos y variados, $y$ distinguen entre profesionales afianzados de un campo que se ponen a anunciar ropa y otros productos, y personas anónimas que dan su opinión en redes y profesionalizan esta tarea. Schouten, Janssen y Verspaget (2020) consideran que los segundos pueden ser más efectivos, porque se sienten más representados y sienten más confianza, mientras que no se explique la relación comercial del influencer con la marca. Por su parte, Feng, Chen y Kong (2020) analizan 7.745 posts de diez influencers de moda para adultos y establecen parte de su éxito en el uso de narrativas persuasivas. Palomeque Recio (2020) ahonda en la conversión de los influencers de moda hacia nuevos temas, por el confinamiento socio-sanitario de la COVID-19. A través de la cuenta de la influencer Chiara Ferragni, aborda la importancia de tratar también en Instagram la domesticidad y paternidad/maternidad, dos temas que existen profusamente en las dos cuentas estudiadas, pero que se abordarán en futuros estudios.

\section{Resultados: @cristiano y @leomessi en Instagram}

En diciembre de 2020, Cristiano Ronaldo posee 247 millones de seguidores en Instagram, con 2.960 publicaciones, y sólo sigue 462 cuentas. La descripción de su cuenta sólo tiene el enlace a su web oficial (www.cristianoronaldo.com) y en su canal de Instagram TV, sólo hay 5 vídeos, uno de ellos repetido pero con distinto filtro. Para el periodo estudiado, el futbolista publicó 257 posts con esta distribución:

- 75 publicaciones promocionales (el 29,2\% sobre el total).

- 182 publicaciones no promocionales (el 70,8\% sobre el total).

- 51.756 comentarios de media por post ( $0,023 \%$ de sus seguidores le comentan).

- 6.954.224 likes de media por post (3,10\% de sus seguidores le dan like)

- El 42,7\% de las promociones son en vídeo y el resto, en imagen (57,3\%). 
- A sus equipos, la selección nacional de fútbol de Portugal y la Juventus Football Club S.p.A. (Juventus de Turín), les dedica el 35\% de sus publicaciones.

En el mes de diciembre de 2020, Leo Messi posee 172 millones de seguidores, con sólo 653 publicaciones, y sigue otras 234 cuentas. La descripción de su cuenta expresa lo siguiente: "Bienvenidos a la cuenta oficial de Instagram de Leo Messi / Welcome to the official Leo Messi Instagram account" y ofrece el enlace a su tienda oficial (www.themessistore.com). Su canal de Instagram TV sólo tiene 2 vídeos. Y para el periodo estudiado, de julio de 2019 a julio de 2020, el futbolista publicó 134 posts con esta distribución:

- 39 publicaciones promocionales (el 29,1\% sobre el total).

- 95 publicaciones no promocionales (el 70,9\% sobre el total).

- 4.288.415 likes de media por post (2,77\% de sus seguidores le dan like).

- A sus equipos, la selección nacional de fútbol de Argentina y el Fútbol Club Barcelona, les dedica el $52,23 \%$ de sus publicaciones.

Sobre los patrocinios, los dos jugadores de fútbol visten de Nike y Adidas, aunque sean competencia directa. Cristiano Ronaldo lleva prendas deportivas de Nike cuando juega con su selección; y viste Adidas cuando juega con la Juventus, aunque patrocina a Nike en muchas de sus fotografías, a título personal. Messi viste Nike en el equipo del Barça y Adidas con la selección argentina y en su tiempo libre, pues es imagen personal de la marca desde 2006. Sobre esta circunstancia, el 29 de noviembre de 2020, con motivo del fallecimiento de Diego Armando Maradona, Messi marcó el cuarto gol de su equipo contra el Club Atlético Osasuna, en partido de La Liga Santander de fútbol español de Primera División. Para celebrar el tanto, el argentino se quitó su camiseta oficial de Nike y mostró la camiseta que llevaba debajo: una camiseta de Adidas del Club Atlético Newell's Old Boys, que había pertenecido al mismo Maradona. De acuerdo al artículo 91 del Código Disciplinario del Comité de Competición de la Real Federación Española de Fútbol, este gesto está penado con tarjeta amarilla y multa de 600 euros. A pesar de las peticiones por tratarse de un homenaje, a la fecha de cierre de este trabajo, la sanción se mantiene y en paralelo, el gesto se viralizó en redes sociales pues se entendía que también Nike podría demandar al argentino por vestir otra marca al mismo tiempo.

Más allá de esta anécdota, y volviendo al análisis, hemos de profundizar en los resultados cualitativos. Cristiano Ronaldo, aparte de la ropa deportiva, luce ropa de gala, ropa informal, relojes y perfumes. La ropa de gala no aparece en los posts con la marca patrocinada, ni etiquetada en la foto, ni en la descripción. Sin embargo, por otras vías, la audiencia sí conoce las marcas de ropa que viste el futbolista portugués, ya sea por la cuenta de Instagram de la marca o porque lo difundan los medios de comunicación. Su marca de cabecera para asistir a eventos es Armani (Armani Privé y Giorgio Armani), aunque también ha vestido ropa de gala de otras marcas, como la francesa Jacquemus o las italianas Dolce \& Gabbana, Gucci y Prada. En cuanto a la ropa deportiva, algunas veces luce camisetas y polos sin logos, y en otras ocasiones, luce ropa reconocible de su propia marca, CR7 (Figura 1). 

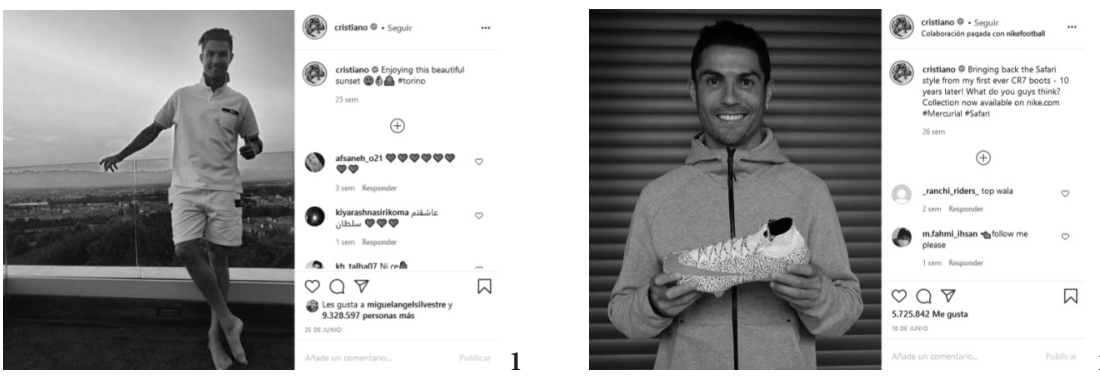

Figura 1. Instagram de Cristiano Ronaldo, 25 de junio de 2020. Disponible en: https:/www.instagram.com /p/CB3ihP3ge07/?utm_source=ig_web_copy_link. Figura 2. Instagram de Cristiano Ronaldo, 16 de junio de 2020. Disponible en: https://www.instagram.com/p/CBfyEClDLD8/?utm_source=ig_web_copy_link

Otra gran parte de las fotografías con ropa deportiva la ocupan productos de Nike, que ya había sido nombrada en líneas anteriores. En el caso del futbolista portugués, se da la curiosa situación de que es imagen de Nike y viste esta camiseta con la selección portuguesa; pero también viste la camiseta de la competencia, Adidas, cuando juega con la Juventus. En los posts de Nike, se le puede ver anunciando sus botas, usando hashtags del modelo concreto de zapatillas, pero sin usar hashtags de la marca ni etiquetar a Nike (Figura 2). El otro gran apartado de publicaciones se refiere a su marca, CR7, ya citada previamente, y que existe desde el año 2007. Es una marca global, con varias líneas de producto, que el futbolista viste en sus fotografías y etiqueta tanto sobre la propia fotografía, como en la descripción con hashtags. La marca CR7 incluye Underwear, Footwear y Denim para niño (Boys) y varón adulto (Mens), y la línea Cristiano Ronaldo Fragances, con los perfumes CR7 Game On, CR7 Play It Cool, CR7, Legacy y Legacy Private Edition.

Por su parte, Leo Messi ha vestido de gala con esmoquin y traje de Armani, Dolce \& Gabbana y Moschino. Cuando aparece de manera informal, suele vestir de Adidas, marca de la que es embajador desde 2006, o de su marca personal: The Messi Store, que también tiene una cuenta bastante activa en Instagram (@themessistore). Esta cuenta sólo posee, en diciembre de 2020, 1,1, millones de seguidores en la red social, con 228 publicaciones. No tienen canal de IGTV pero sí han publicado 6 reels, entre el 9 de octubre y el 10 de diciembre de 2020. Volviendo al Instagram personal de Messi, cuando viste de su marca, cita la marca en la descripción de la foto o la etiqueta sobre la propia foto. Aunque sea su propio sello, dice que se trata de un patrocinio remunerado: "Colaboración pagada con themessistore" (Figura 3). 

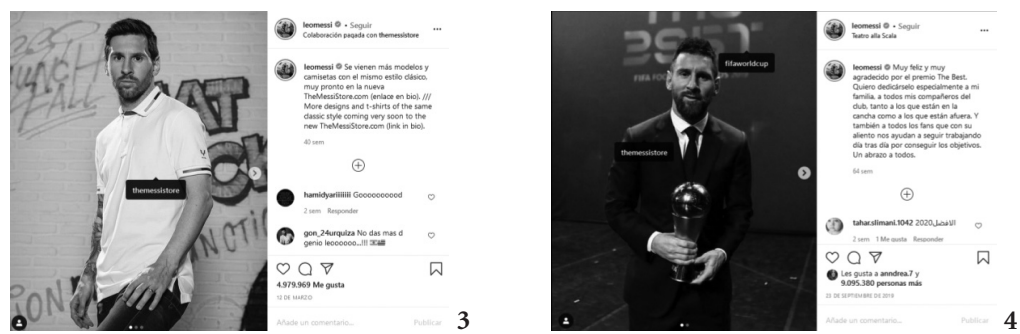

Figura 3. Instagram de Leo Messi, 12 de marzo de 2020. Disponible en: https://www.instagram.com/p/ B9pPpHMKvqL/?utm_source=ig_web_copy_link. Figura 4. Instagram de Leo Messi, 23 de septiembre de 2019. Disponible en: https://www.instagram.com/p/B2xLPj1i3Gk/?utm_source=ig_web_copy_link

Esta decisión de comunicar el patrocinio de sus propios productos se adelanta a la legislación europea que se está pidiendo sobre este asunto, para regular de una vez la publicidad en Instagram por parte de celebridades e influencers. Al cerrar este trabajo, en España sólo existe el Código sobre el uso de influencers en la publicidad, tras la aprobación del protocolo suscrito por Autocontrol y los Ministerios de Asuntos Económicos y de Consumo. Este protocolo es una recomendación de obligado cumplimiento solamente para las empresas asociadas a Autocontrol y supone sanciones ejemplares dentro de ese organismo, pero no sanciones administrativas ni penales del sistema judicial español.

En la cuenta de Instagram de Messi también se encuentran fotografías del futbolista vestido de etiqueta y en sus últimas apariciones, vestía traje, camisa y corbata de su propia marca. Al contrario que CR7, The Messi Store cuenta con líneas para un público más amplio: Hombres, Mujeres, Niños y Accesorios (https://www.themessistore.com/es). Además, el futbolista aparece en varias fotografías con relojes de Jacob \& Co, que creó un modelo exclusivo de reloj de muñeca con su nombre: JacobઐMessi Limited Edition.

Sobre la ropa de gala, como se comentaba anteriormente, Messi viste de su marca o viste de otras marcas que no etiqueta directamente (Figura 4).

Esta decisión de vestir trajes de su propia marca bien puede responder a dos estrategias: aumentar las ventas de ropa e indirectamente, hacer que el perfil del futbolista sea más bajo, con vestimentas menos llamativas que en el pasado y que no den lugar a tantos comentarios. En 2012, el jugador argentino acudió a la gala del Balón de Oro con un esmoquin a medida en dos piezas, formado por un pantalón negro y una chaqueta de corte Sicilia, de la marca italiana Dolce \& Gabbana. La chaqueta y la pajarita llevaban lunares blancos y como el jugador resultó ganador del premio, las fotos y las críticas dieron la vuelta al mundo. En la misma gala, pero en la edición de 2014, volvió a generar comentarios con otro esmoquin de la misma marca, esta vez en rojo irisado. A pesar de que el traje incluso fue tema de memes virales, el astro repitió tendencia en la gala siguiente, con un traje muy similar, más morado que rojo, y con estampado de jacquard en lurex. Sin embar- 
go, en el periodo estudiado, los trajes y la ropa de gala son negros y clásicos, con camisas claras, blancas casi en su totalidad, y sin histrionismos.

\section{Conclusiones y prospectivas}

Tras los hallazgos, se comentan las conclusiones y las áreas para nuevas parcelas de investigación, que ha abierto y propuesto este trabajo.

El objetivo de explorar de manera mixta a nivel cuantitativa y cualitativa, las cuentas de Instagram de Cristiano Ronaldo (@cristiano) y Lionel Messi (@leomessi) se ha satisfecho contabilizando las publicaciones, los likes, los comentarios, los hashtags, el tipo de promoción, los productos anunciados o la dedicación de cada jugador a imágenes propias o a imágenes de su equipo. Aunque cada diferencia en estos items se ha subrayado ya, hay dos ideas interesantes para seguir investigando: Cristiano Ronaldo tiene más seguidores pero para conseguirlos, en el periodo estudiado, casi dobló a Messi en el número de publicaciones; y Messi dedicó más tiempo que Ronaldo a publicar posts sobre sus dos equipos, teniendo en cuenta que justo al acabar la investigación, vivió una crisis mediática al manifestar su deseo de abandonar el F.C. Barcelona. Estas dos circunstancias nos hacen valorar para futuras investigaciones la validez de la ratio publicaciones/seguidores y la creación de un medidor de compromiso del jugador con sus equipos, para cuantificar el sentimiento de compromiso o pertenencia como clave de éxito, teniendo en cuenta que el fútbol es un deporte de grupo.

La idea de detectar y comentar las diferencias entre las dos cuentas: número de seguidores, número de publicaciones, productos de moda que anuncian, sector de moda que anuncian, formas de comunicar los patrocinios y las colaboraciones, e impacto también habría quedado cubierta con los resultados. Para futuras investigaciones, el análisis podría contener una comparativa de la estrategia que siguen Ronaldo y Messi, frente a otras celebridades o influencers que anuncian la misma marca o el mismo producto, cuando no se trate de algo personalizado, ni exclusivo.

Igualmente, dado el éxito global de los dos jugadores, este trabajo plantea el interrogante de si esas marcas actúan de manera glocal: contratan a los astros para lograr una influencia global pero también a influencers locales o nacionales, para estrategias concretas en algunos países o continentes, quizás con personas que sean más cercanas. Otro punto interesante y necesario de este objetivo sería abordar los beneficios que consiguen las marcas de lujo que patrocinan los dos jugadores. Algunas requieren un nivel adquisitivo muy alto para su consumo, que está lejos de la audiencia general de las dos celebridades. Sería necesario preguntarse si estas alianzas comerciales quieren aumentar efectivamente las ventas o simplemente, hacer que las marcas se sitúen en un estatus casi inalcanzable.

El objetivo de explorar si se utilizan más fotos o más vídeos se ha satisfecho con una detección mayoritaria de las primeras frente a los segundos. La cantidad de vídeos en las publicaciones es muy pequeña respecto a la cantidad de fotografías; Ronaldo tiene canal de IGTV solamente con 5 vídeos y Messi no tiene este canal. Sí es cierto que en la cuenta de The Messi Store, por el momento, hay 6 reels pero son muy pocos para hacer una inves- 
tigación exhaustiva. Sabiendo que TikTok ha sido la red social más beneficiada por la crisis de la COVID-19 y estando a la espera de confirmar que podría haber doblado su número de usuarios en 2020, sería imprescindible analizar por qué estas celebridades no usan tanto el vídeo, por qué no se han animado a usar los reels y por qué no cuentan todavía con un perfil oficial en TikTok. Los expertos consideran que TikTok será pronto la red favorita de los centennials y quizás estos no son el público diana para vender productos por no disponer de posibilidades económicas propias y por ello, podrían no ser tan interesantes para estas celebridades. Además, hay que debatir si TikTok parece un medio demasiado con mucho humor y mucha crítica; y quizás los jugadores no se hayan animado a tener una cuenta en la red social por miedo al juicio negativo, a la parodia o al meme, como ya les ha ocurrido a cuentas institucionales que han sido duramente criticadas por estrenar perfiles en la red social china.

Por último, el fin de dilucidar la influencia de los deportistas como modelos de ropa, más allá de su primera actividad profesional habría quedado también validado. La ropa es el producto más anunciado por los dos. Tanto es así que ambos han creado un negocio de ropa con su nombre. Cristiano Ronaldo lo hizo con su marca CR7 en 2007; y Messi lanzó The Messi Store en septiembre de 2019. Los dos dedican gran parte de sus fotografías a anunciar la ropa de sus respectivas marcas. Hay un pequeño matiz y es que Messi ofrece fotografías corporativas directamente sacadas de la web o del catálogo de su tienda, mezclándolas con fotos casuales o espontáneas. Cristiano Ronaldo, por el contrario, no replica en Instagram las fotografías comerciales de su web y sí viste su ropa en sus posts, pero en entornos de la vida diaria. Sería interesante analizar por qué cada uno sigue una estrategia tan distinta y qué efectos de engagement tiene sobre la audiencia.

Igualmente, sería muy atrayente valorar qué prendas propias hacen competencia directa a prendas de otras marcas de las que son imagen, y qué competencia se establece entre ellas. Este análisis podría incluir una medición por rangos de precios, ya que los dos futbolistas anuncian igualmente productos asequibles de sus marcas, que trajes de gala de lujo que superan los 3.000 dólares por pieza. En el caso de Messi, concretamente, se ha detectado una búsqueda de un perfil bajo, con apariciones con ropa de etiqueta muy sobria, de su propia marca y alejada de los grandes trajes brillantes con los que recogió sus galardones de Balón de Oro. Sería necesario entender los porqués y las consecuencias de este cambio de estrategia; y dilucidar si esta reducción en el presupuesto de vestimenta se incrementa, o no, tras la crisis de la COVID-19, quizás en una búsqueda de mayor empatía con la audiencia.

\section{Referencias bibliográficas}

Bergkvist, L.; Hjalmarson, H. \& Mägi, A. W. (2016). A new model of how celebrity endorsements work: attitude toward the endorsement as a mediator of celebrity source and endorsement effects. International Journal of Advertising, 35(2), 171-184. https://doi.or g/10.1080/02650487.2015.1024384 
Bernárdez Rodal, A.; Padilla Castillo, G. \& Sosa Sánchez, R. P. (2019). From Action Art to Artivism on Instagram: Relocation and instantaneity for a new geography of protest. Catalan Journal of Communication \& Cultural Studies, 11(1), 23-37. doi: 10.1386/cjcs.11.1.23_1

Clary, P. C.; Markham, M. S. \& Myers-Bowman, K. S. (2020). Relationships are Key: Family Life Educators' Use of Social Networking Sites. Journal of Technology in Human Services, 38(2), 112-136. doi: 10.1080/15228835.2020.1713279

Feng, Y.; Chen, H. \& Kong, Q. (2020). An expert with whom i can identify: the role of narratives in influencer marketing. International Journal of Advertising, online, 1-22. https://doi.org/10.1080/02650487.2020.1824751

IAB Spain (2019a). Estudio anual de redes sociales 2019. https://iabspain.es/estudio/estudio -anual-de-redes-sociales-2019/

IAB Spain (2019b). Top Tendencias Digitales 2020. https://iabspain.es/estudio/top-tenden cias-digitales-2020/

INE (2020). Población que usa Internet (en los últimos tres meses). Tipo de actividades realizadas por Internet. https://www.ine.es/ss/Satellite?L=es_ES\&c=INESeccion_C\&cid=1 $259925528782 \& \mathrm{p}=1254735110672 \&$ pagename $=$ ProductosYServicios\%2FPYSLayout

InfoAdex (2020). Estudio InfoAdex de la Inversión Publicitaria en España 2020. https://www. infoadex.es/home/

Kijek, T.; Angowski, M. \& Skrzypek, A. (2020). Millennials Use of Social Media in Product Innovation Purchasing Processes. Journal of Computer Information Systems, 60(1), 9-17. doi: 10.1080/08874417.2019.1604104

Padilla Castillo, G. y Oliver González, A. B. (2018). Instagramers e influencers. El escaparate de la moda que eligen los jóvenes menores españoles. Revista Internacional de Investigación en Comunicación aDResearch ESIC, 18(18), 42-59. DOI: https://doi.org/10.7263/ adresic-018-03

Palomeque Recio, R. (2020). Postfeminist performance of domesticity and motherhood during the COVID-19 global lockdown: the case of Chiara Ferragni. Feminist Media Studies, online, 1-22. https://doi.org/10.1080/14680777.2020.1830147

Schouten, A. P.; Janssen, L. \& Verspaget, M. (2020). Celebrity vs. Influencer endorsements in advertising: the role of identification, credibility, and Product-Endorser fit. International Journal of Advertising, 39(2), 258-281. https://doi.org/10.1080/02650487.2019.1634898

Socialpubli (2020). I Estudio de Moda \& Influencers. https://socialpubli.com/es/blog/estudio -moda-influencers/

The Social Media Family (2020). VI Informe sobre los usuarios de Facebook, Twitter e Instagram en España. https://thesocialmediafamily.com/news-posts/vi-informe-sobre-los-usuarios -de-facebook-twitter-e-instagram-en-espana/

Van Nispen, J.; Fraguas, M.; Álvarez, D.; Gómez, A.; Alcaide, J. C.; Almarza, C.; Avello, C.; Arias, S.; Baró, D.; González, Á.; Garmendia, G.; Labrador, J. C.; Martín, A.; Martínez, L.; Nowenstein, P.; Piedrahita, J.; Plágaro, J.; Sánchez, J.; Torrejón, D. y Fuente, M. C. (2012). Diccionario LID Marketing directo e interactivo. Madrid, España: LID Editorial.

We Are Social y Hootsuite (2020). Digital in 2020. https://wearesocial.com/digital-2020 


\begin{abstract}
Instagram is a fashion showcase with more than 1 billion users. This work investigates the accounts of Cristiano Ronaldo and Lionel Messi, as two of the influencers with the most followers on Instagram. Their activity in the social network of photographs is analyzed quantitatively and qualitatively, during a calendar year, from July 2019 to July 2020. It is concluded that promotional publications do not exceed $30 \%$ of total publications; only $3 \%$ of the followers give a like; less than $1 \%$ comment; and photo posts still prevail over video posts, although Instagram offers several formats (short videos, IGTV, reels and featured stories).
\end{abstract}

Keywords: Instagram - influencers - fashion - sport - football - Ronaldo - Messi - social networks - advertising - images.

Resumo: Instagram é uma vitrine de moda com mais de 1 bilhão de usuários. Este trabalho investiga os relatos de Cristiano Ronaldo e Lionel Messi, como dois dos influenciadores com mais seguidores no Instagram. A sua atividade na rede social de fotografias é analisada quantitativa e qualitativamente, durante um ano civil, de julho de 2019 a julho de 2020. Conclui-se que as publicações promocionais não ultrapassam 30\% do total de publicações; apenas 3\% dos seguidores gostam; menos de 1\% comentário; e as postagens de fotos ainda prevalecem sobre as postagens de vídeo, embora o Instagram ofereça vários formatos (vídeos curtos, IGTV, carretéis e histórias em destaque).

Palavras chave: Instagram - influenciadores - moda - esporte - futebol - Ronaldo - Messi - redes sociais - publicidade - imagens.

[Las traducciones de los abstracts fueron supervisadas por el autor de cada artículo] 